\title{
Characterization of corrosion products formed on carbon steel in hydrochloric acid medium by 4-(dimethylamino)-1-(6-methoxy- 6-oxohexyl)pyridinium bromide
}

\author{
H. Lgaz, ${ }^{1,2}$ A. Anejjar, ${ }^{2}$ R. Salghi, ${ }^{2} *$ S. Jodeh, ${ }^{3} *$ M. Zougagh, ${ }^{4,5}$ I. Warad, ${ }^{3}$ \\ M. Larouj ${ }^{1}$ and P. Sims ${ }^{6}$ \\ ${ }^{1}$ Laboratory separation processes, Faculty of Science, Ibn Tofail University, PO Box 242, \\ Kenitra, Morocco \\ ${ }^{2}$ Laboratory of Applied Chemistry and Environment, ENSA, Ibn Zohr University, \\ PO Box 1136, 80000 Agadir, Morocco \\ ${ }^{3}$ Department of Chemistry, An-Najah National University, P. O. Box 7, Nablus, Palestine \\ ${ }^{4}$ Regional Institute for Applied Chemistry Research, IRICA, E-13004, Ciudad Real, Spain \\ ${ }^{5}$ Castilla-La Mancha Science and Technology Park, E-02006, Albacete, Spain \\ ${ }^{6}$ Bob L. Herd Department of Petroleum Engineering, Texas Tech University, box 43111, \\ Lubbock, Texas \\ *E-mail:r.salghi@uiz.ac.ma,sjodeh@hotmail.com
}

\begin{abstract}
The inhibition of corrosion of carbon steel in $1 \mathrm{M} \mathrm{HCl}$ by the synthesized ionic liquid 4(dimethylamino)-1-(6-methoxy-6-oxohexyl)pyridinium bromide (DMOPB) is performed by electrochemical, gravimetric techniques and surface analysis techniques. The efficiency of inhibition increases with the inhibitor concentration and reached $93 \%$ at $10^{-3} \mathrm{M}$. The polarization data indicate that the tested inhibitor is a mixed type. The adsorption of the inhibitor on the surface of the steel in $1 \mathrm{M} \mathrm{HCl}$ follows the adsorption isotherm Langmuir. The study of the effect of temperature $(303-333 \mathrm{~K})$ on the behavior of the steel in $1 \mathrm{M}$ $\mathrm{HCl}$ in the absence and presence of $10^{-3} \mathrm{M}$ of the inhibitor shows that the inhibitory efficiencies increase with temperature in this studied range. The corresponding activation parameters in the absence and presence of inhibitor were determined and discussed. The inhibition efficiency was closely related to orbital energies (EHOMO and ELUMO). The correlation between quantum parameters and experimental inhibition efficiency has been validated. Scanning electron microscopy images revealed that the inhibitor formed protective film on mild steel surface.
\end{abstract}

Key words: ionic liquid, inhibition, carbon steel, acid, free energy.

Received: April 8, 2016. Published: June 14, 2016.

doi: $\underline{10.17675 / 2305-6894-2016-5-3-3}$ 


\section{Introduction}

The use of inhibitors is one of the usual methods for protection of metallic materials against corrosion in acidic environments. Among these applications we can mention the acid pickling, industrial cleaning with acid and descaling with acid. Due to the aggressiveness of most acidic solutions, inhibitors are commonly used to stop or reduce the corrosive attack of metallic materials. Adsorption inhibitor is influenced by the nature and surface charge of the metal, the type of aggressive electrolyte and by the chemical structure of the inhibitors, the nature of the surface, the temperature and pressure of the reaction, the flow velocity as well as composition of the aggressive environment [1]. The main types of interactions between the inhibitor and the metal surface are physical adsorption and chemisorption. The adsorption of the inhibitor is linked to the presence of heteroatoms such as nitrogen, oxygen, phosphorus and sulfur and/or triple bonds or aromatic rings in their molecular structure [2]. Inhibitors has basic nitrogen inhibit at the same time either corrosion or penetration of hydrogen [3]. In the past two decades, the organic compounds with melting points of bottom which known as ionic liquids, have been considered as important theme of research in both industry and the academic community [4]. Many industrial applications of these Ionic liquids have been found in organic synthesis, catalysis [5] chemical extraction [6] corrosion [7], biochemistry [8]. Pyridinium and pyridaziniumbased ionic liquids are reported to show corrosion resistant behavior on copper [9] and mild steel [10]. The inhibitors can decrease the dissolution of metals, affecting the kinetics of the reactions which create the corrosion process. The good results obtained with ionic liquids compounds as green inhibitor in the inhibition of acid media metal corrosion, incite us to evaluate other organic compounds to test their inhibition action [11]. In this work, inhibitive action of the new synthesized ionic liquids DMOPB on corrosion behaviour of carbon steel in $1 \mathrm{M} \mathrm{HCl}$ has been studied by using weight loss measurements and electrochemical techniques such as electrochemical impedance spectroscopy (EIS) and potentiodynamic polarization. The effect of temperature on the inhibition efficiency of the selected schiff base has been studied systematically. In addition, quantum chemical calculations were made to add theoretical support to experimental results. The structural formula of the inhibitor examined is given in Figure 1.

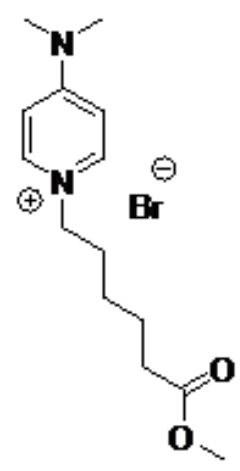

Figure 1. 4-(Dimethylamino)-1-(6-methoxy-6-oxohexyl)pyridinium bromide (DMOPB). 


\section{Materials and methods}

\subsection{Materials and solutions}

The steel that we used in this study is a carbon steel (Euronorm: C35E carbon steel and US specification: SAE 1035) with a chemical composition (in wt $\%$ ) of $0.370 \% \mathrm{C}, 0.230 \% \mathrm{Si}$, $0.680 \% \mathrm{Mn}, 0.016 \% \mathrm{~S}, 0.077 \% \mathrm{Cr}, 0.011 \% \mathrm{Ti}, 0.059 \% \mathrm{Ni}, 0.009 \% \mathrm{Co}, 0.160 \% \mathrm{Cu}$ and the remainder iron $(\mathrm{Fe})$. The carbon steel samples were pre-treated prior to the experiments by grinding with emery paper $\mathrm{SiC}(320,800$ and 1200); rinsed with distilled water, degreased in acetone, washed again with bidistilled water and then dried at room temperature before use. The acid solutions $(1.0 \mathrm{M} \mathrm{HCl})$ were prepared by dilution of an analytical reagent grade $37 \% \mathrm{HCl}$ with double-distilled water. The DMOPB concentration are prepared by dissolving the DMOPB weighted in the acid solution and the range of DMOPB concentration employed was $10^{-6} \mathrm{M}$ to $10^{-3} \mathrm{M}$. The reagents were purchased from Aldrich and used as received. All solvents were of HPLC grade.

\subsection{Synthesis of 4-(dimethylamino)-1-(6-methoxy-6-oxohexyl)pyridinium bromide}

\section{(DMOPB) under ultrasonic irradiation}

4-(Dimethylamino)pyridinium (1 eq.) and methyl 6-bromohexanoate (1 eq.) were placed in a closed container and exposed to irradiation for five hours at $70^{\circ} \mathrm{C}$ using a sonication bath. Completion of the reaction was marked by the precipitation of a solid from the initially obtained clear and homogenous mixture in toluene. The obtained product was isolated by filtration and washed three times with ethyl acetate solution to remove any unreacted starting materials and solvent. Afterwards, the pyridazinium salt was washed with ethyl acetate. Finally the product was dried at a reduced pressure to remove all volatile organic compounds.

All new compounds were synthesized and characterized by ${ }^{1} \mathrm{H}$ NMR, ${ }^{13} \mathrm{C}$ NMR, IR, and LCMS. ${ }^{1} \mathrm{H}$ NMR $(400 \mathrm{MHz})$ and ${ }^{13} \mathrm{C}$ NMR $(100 \mathrm{MHz})$ spectra were measured in DMSO at room temperature. Chemical shifts $(\delta)$ were reported in ppm to a scale calibrated for tetramethylsilane (TMS), which is used as an internal standard. The LCMS spectra were measured with a Micromass, LCT mass spectrometer. IR spectra were recorded in $\mathrm{NaCl}$ disc on a Schimadzu 8201 PC, FTIR spectrophotometer $\left(v_{\max }\right.$ in $\left.\mathrm{cm}^{-1}\right)$. The ultrasound-assisted reactions were performed using a controllable laboratory ultrasonic bath.

\subsection{Characterization of 4-(dimethylamino)-1-(6-methoxy-6-oxohexyl)pyridinium bromide $(D M O P B)$}

The structures of compound DMOPB are confirmed by using IR, ${ }^{1} \mathrm{H}$ NMR, ${ }^{13} \mathrm{C}$ NMR and LCMS. White crystals, m.p. $102-105^{\circ} \mathrm{C},{ }^{1} \mathrm{H}$ NMR $\left(\mathrm{D}_{2} \mathrm{O}, 400 \mathrm{MHz}\right.$,): $\delta=1.12(\mathrm{t}, 3 \mathrm{H}), 1.21$ (quintet, 2H), 1.52 (quintet, 2H), 1.77 (sextet, 2H), 2.26 (quintet, $2 \mathrm{H}), 3.11(\mathrm{~s}, 6 \mathrm{H}), 4.04(\mathrm{~m}$, $4 \mathrm{H}), 4.69(\mathrm{~s}, 2 \mathrm{H}), 6.80(\mathrm{~d}, 2 \mathrm{H}), 7.94(\mathrm{~d}, 2 \mathrm{H}) ;{ }^{13} \mathrm{C} \mathrm{NMR}\left(\mathrm{D}_{2} \mathrm{O}, 100 \mathrm{MHz}\right): \delta=13.4\left(\mathrm{CH}_{3}\right)$, 
$23.7\left(\mathrm{CH}_{2}\right), 24.6\left(\mathrm{CH}_{2}\right), 29.6\left(\mathrm{CH}_{2}\right), 33.7\left(\mathrm{CH}_{2}\right), 39.6\left(\mathrm{CH}_{3}\right), 57.3\left(\mathrm{CH}_{2}\right), 61.5\left(\mathrm{CH}_{2}\right), 107.5$ $(\mathrm{CH}), 141.3(\mathrm{CH}), 156.2(\mathrm{C}), 176.6(\mathrm{C})$; LCMS (M-Br) 251.3 found for $\mathrm{C}_{14} \mathrm{H}_{23} \mathrm{~N}_{2} \mathrm{O}_{2}^{+}$.

\subsection{Weight loss and electrochemical measurement}

Gravimetric measurements were carried out in a double walled glass cell equipped with a thermostated cooling condenser. The solution volume was $100 \mathrm{ml}$. The steel specimens used had a rectangular form $\left(2 \times 2 \times 0.08 \mathrm{~cm}^{3}\right)$. The polarization studies were carried out in $1 \mathrm{M} \mathrm{HCl}$ acid solution, potentiodynamically using a Voltalab PGZ 100 (TacusselRadiometer) controlled by a computer piloted by Voltamaster software under static condition and employing a three electrodes cell assembly. A saturated calomel electrode (SCE) and platinum were used as reference electrode and auxiliary electrodes respectively. We used a carbon steel as a working electrode with a dimensions $(0.700 \mathrm{~cm} \times 0.0235 \mathrm{~cm})$. All solutions were prepared with bidistilled water. The experiments were performed in aerated solutions at $303 \mathrm{~K}$ using a thermostatic bath and the polarization curves are obtained from $-800 \mathrm{mV}$ to $-200 \mathrm{mV}$. Electrochemical impedance spectroscopy (EIS) was carried out at $E_{\text {corr }}$ after $30 \mathrm{~min}$ of immersion in solution after the determination of steady-state current at a given potential. Sine voltage $(10 \mathrm{mV})$ peak to peak, at frequencies between $100 \mathrm{KHz}$ and $10 \mathrm{MHz}$ was superimposed on the rest potential. The impedance diagrams are given in the Nyquist representation.

\subsection{Quantum chemical calculations}

All theoretical calculations were performed using DFT (density functional theory) with the Beck's three parameter exchange functional along with the Lee-Yang-Parr nonlocal correlation functional (B3LYP) [12] with 6-31G* basis set is implemented in Gaussian 03 program package [13]. This approach is shown to yield favorable geometries for a wide variety of systems. The following quantum chemical parameters were calculated from the obtained optimized molecular structure: the energy of the highest occupied molecular orbital $\left(E_{\mathrm{HOMO}}\right)$, the energy of the lowest unoccupied molecular orbital $\left(E_{\mathrm{LUMO}}\right)$, the energy band gap $\left(\Delta E_{\text {gap }}=E_{\mathrm{HOMO}}-E_{\mathrm{LUMO}}\right)$, the dipole moment $(\mu)$, electron affinity (EA), ionization potential (IE), the fraction of electrons transferred $(\Delta N)$ and the total energy (TE).

\subsection{Scanning electron microscopy imaging}

The morphology of the bare carbon steel, carbon steel with and without inhibitor was characterized by Scanning Electron Microscopy (Hitachi TM-1000) with an accelerating voltage of $15 \mathrm{kV}$. 


\section{Results and discussion}

\subsection{Polarization results}

The cathodic and anodic polarization curves of carbon steel in $1 \mathrm{M} \mathrm{HCl}$ medium deaerated with and without addition of the DMOPB inhibitor tested at different concentrations are shown in Figure 2. Electrochemical parameters derived from these curves are shown in Table 1. The inhibition efficiency of this compound is defined by the relation:

$$
E_{\mathrm{I}} \%=\frac{I_{\text {corr }}-I_{\text {corr (inh) }}}{I_{\text {corr }}} \times 100,
$$

where $I_{\text {corr }}$ and $I_{\text {corr(inh) }}$ represent the corrosion current densities determined by extrapolation of Tafel straight lines in $1 \mathrm{M} \mathrm{HCl}$ medium, respectively, without and with addition of DMOPB inhibitor.

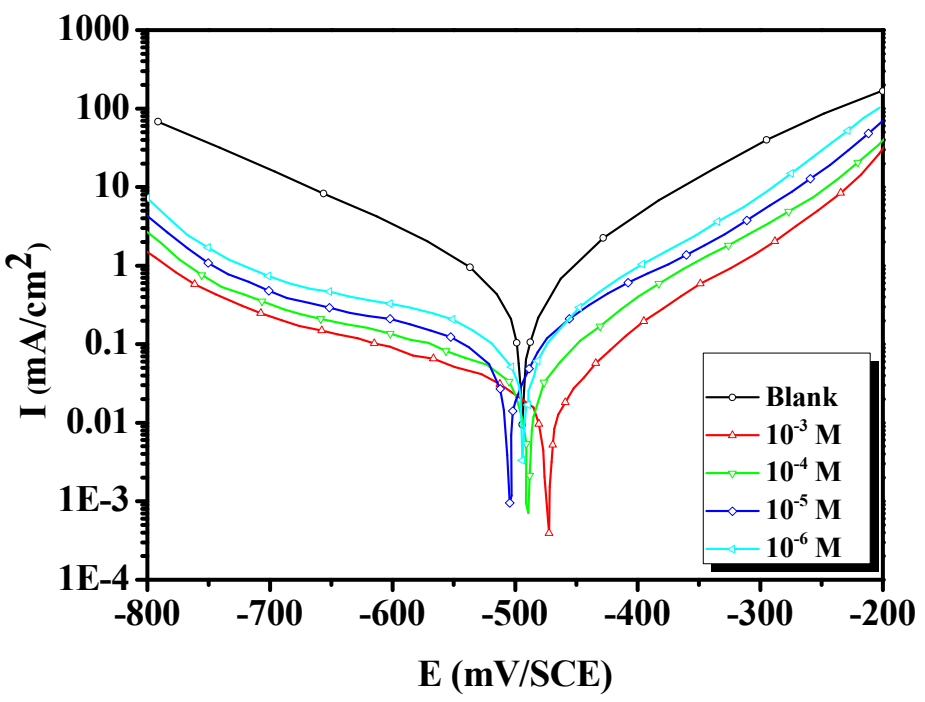

Figure 2. Polarization curves of carbon steel in $1.0 \mathrm{M} \mathrm{HCl}$ for various concentrations of DMOPB at $303 \mathrm{~K}$.

Table 1. Polarization data of carbon steel in $1.0 \mathrm{M} \mathrm{HCl}$ without and with various concentrations of DMOPB at $303 \mathrm{~K}$.

\begin{tabular}{cccccc}
\hline Inhibitor & $\begin{array}{c}\text { Concentration } \\
(\mathbf{M})\end{array}$ & $\begin{array}{c}-\boldsymbol{E}_{\mathbf{c o r r}} \\
(\mathbf{m V} / \mathbf{S C E})\end{array}$ & $\begin{array}{c}-\boldsymbol{\beta} \mathbf{c} \\
\left(\mathbf{m V} \mathbf{d e c}^{-\mathbf{1}}\right)\end{array}$ & $\begin{array}{c}\boldsymbol{I}_{\text {corr }} \\
\left(\boldsymbol{\mu} \mathbf{A ~ \mathbf { ~ m } ^ { - 2 }}\right)\end{array}$ & $\begin{array}{c}\boldsymbol{\eta}_{\text {Tafel }} \\
(\mathbf{\%})\end{array}$ \\
\hline Blank & 1.0 & 496 & 162 & 564 & - \\
\hline \multirow{2}{*}{ DMOPB } & $10^{-3}$ & 470 & 156 & 45 & 92 \\
& $10^{-4}$ & 491 & 163 & 52 & 91 \\
& $10^{-5}$ & 502 & 151 & 75 & 87 \\
& $10^{-6}$ & 493 & 169 & 105 & 81 \\
\hline
\end{tabular}


Inspection of Figure 2 and the parameters presented in Table 1 reveal that on increasing inhibitor concentrations, the values of cathodic and anodic current densities decrease. The densities of corrosion currents decrease in the presence of studied inhibitor, so the corrosion rate decreases that's due to the increase in the blocked fraction of the electrode surface by adsorption. It can be also seen that the presence of DMOPB cause significant change in the anodic and cathodic branch. This may be ascribed to adsorption of inhibitor over the corroded surface [14]. The cathodic Tafel lines show similar slope either in presence or absence of DMOPB. It indicates that the mechanism of the cathodic reaction does not change in presence of the inhibitor and the inhibition action is achieved by simple blocking of the iron surface $[15,16]$. The inhibitory efficacy of the DMOPB increases with the concentration and achieved maximum value of the order of $92 \%$ to $10^{-3} \mathrm{M}$.

\section{Weight loss tests}

The carbon steel corrosion rate is determined gravimetrically after 6 hours immersion in $1 \mathrm{M} \mathrm{HCl}$ with and without addition of the inhibitor at various concentrations. The inhibitory efficiency $\left(E_{\mathrm{w}} \%\right)$ of the DMOPB is calculated from the following relationship:

$$
E_{\mathrm{w}} \%=\frac{W_{\text {corr }}-W_{\text {corr (inh) }}}{W_{\text {corr }}} \times 100,
$$

where $W_{\text {corr(inh) }}$ and $W_{\text {corr }}$ are the corrosion rates of carbon steel in the presence and the absence of definite concentration of inhibitor, respectively. The degrees of surface coverage $(\theta)$ at different concentrations of the inhibitor in $1 \mathrm{M} \mathrm{HCl}$ were evaluated from weight loss measures as $\theta=E_{\mathrm{W}}(\%) / 100$. The results of the study are summarized in Table 2 .

Table 2. Corrosion parameters obtained from weight loss measurements for carbon steel in $1.0 \mathrm{M} \mathrm{HCl}$ containing various concentrations of DMOPB at $303 \mathrm{~K}$.

\begin{tabular}{ccccc}
\hline Inhibitor & Concentration $(\mathbf{M})$ & $W_{\text {corr }}\left(\mathbf{m g ~ c m}^{-\mathbf{2}} \mathbf{h}^{-\mathbf{1}}\right)$ & $\boldsymbol{\eta}_{\mathbf{w}}(\mathbf{\%})$ & $\theta$ \\
\hline Blank & 1.0 & 1.065 & - & - \\
& $10^{-3}$ & 0.074 & 93 & 0.93 \\
\multirow{2}{*}{ DMOPB } & $10^{-4}$ & 0.127 & 88 & 0.88 \\
& $10^{-5}$ & 0.149 & 86 & 0.86 \\
& $10^{-6}$ & 0.191 & 82 & 0.82 \\
\hline
\end{tabular}

Analysis of the Table 2 shows that increasing the concentration of the inhibitor was accompanied by a decrease in the rate of corrosion and led to increasing of the inhibition efficiency, this due to the fact that the adsorption coverage increases, which shields the carbon steel surface efficiently from the medium [17]. This decrease was significant even at low concentrations. 


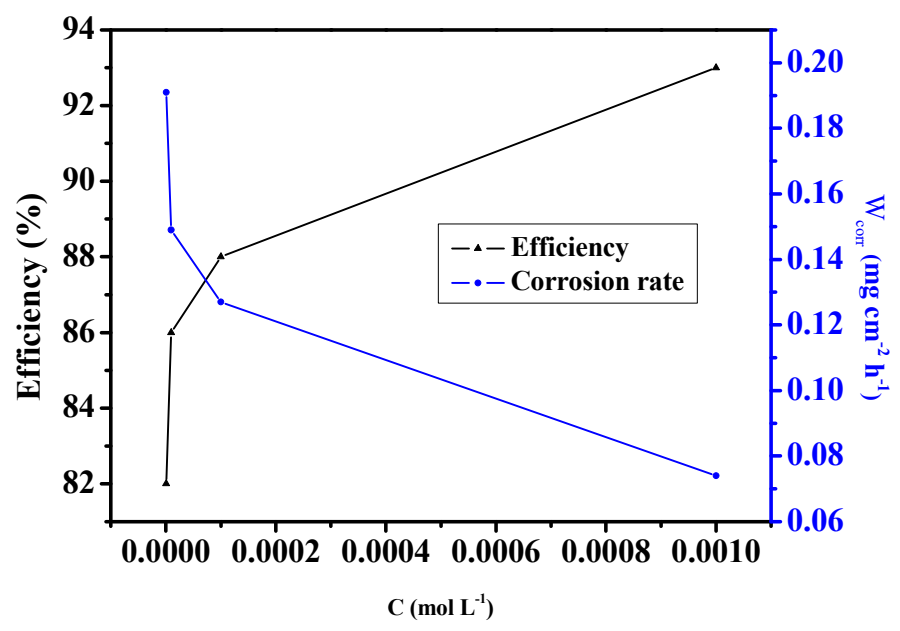

Figure 3. Relationship between the corrosion rates, the inhibition efficiency and inhibitor concentrations for steel after $6 \mathrm{~h}$ immersion in $1.0 \mathrm{M} \mathrm{HCl}$ at $303 \mathrm{~K}$.

Figure 3 illustrates the variation of corrosion rate $W_{\text {corr }}$ and efficiencies with concentration of inhibitor which revealed that pyridinium IL derivative has got significant inhibition ability in $1 \mathrm{M} \mathrm{HCl}$ media. It has been found that this compound inhibits the corrosion of carbon steel in $1 \mathrm{M} \mathrm{HCl}$ solution at all concentrations used in this study. The inhibition efficiency increases with concentration and reached $93 \%$ at $10^{-3} \mathrm{M}$, this result confirms the polarization curves tests results.

\section{Electrochemical impedance spectroscopy measurements}

The impedance spectra obtained in $1 \mathrm{M} \mathrm{HCl}$ in corrosion potential are recorded after 30 min immersion for various concentrations of inhibitor. Nyquist diagrams are shown in Figure 4.

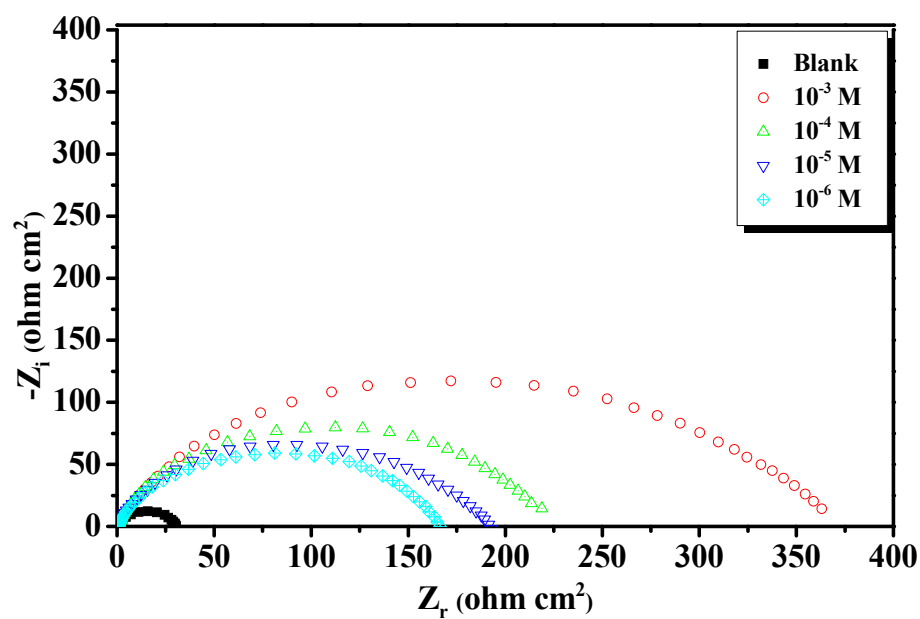

Figure 4. Nyquist diagrams for carbon steel in $1.0 \mathrm{M} \mathrm{HCl}$ containing different concentrations of DMOPB at $303 \mathrm{~K}$. 
The capacitive loops Nyquist diagrams obtained are centered on the real axis, because of the frequency dispersion which can be connected to a surface of heterogeneity which generates a frequency distribution. This heterogeneity results from roughness, impurities, relocations and the adsorption of the inhibitor and/or the formation of porous layers [18]. Furthermore, the diameter of the capacitive loop as charge transfer resistance $\left(R_{\mathrm{ct}}\right)$, in the presence of inhibitor is bigger than that in the absence of inhibitor and increases with the inhibitor concentration. This indicates that the impedance of inhibited electrode increases with the DMOPB concentration. The simplest approach requires that $Z(\omega)$ is represented by a circuit in which the ability of the double layer $\left(C_{\mathrm{dl}}\right)$ and the charge transfer resistance $\left(R_{\mathrm{ct}}\right)$ are introduced in parallel; the resistance of the electrolytic solution $\left(R_{\mathrm{s}}\right)$ is inserted in series in the circuit. This classic approach model is suitable for homogeneous systems and cannot be applied to systems heterogeneous most experimental results show a frequency dispersion weakness [19]. The element constant phase (CPE) which realizes surface inhomogeneities through the $n$ coefficient [20] (Figure 5). The impedance $Z$, applying the CPE is determined from the following relationship:

$$
Z_{(C P E)}=1 / y_{0}(j \omega)^{n},
$$

where $y_{0}$ is the constant of CPE, $\omega$ is the angular frequency, $n$ is the phase shift;

$$
C P E=y_{0}\left(\omega_{\max }\right)^{n-1}, \quad \omega_{\max }=2 \pi f_{\max },
$$

$f_{\max }$ is the frequency at which the imaginary part of the impedance is maximum.

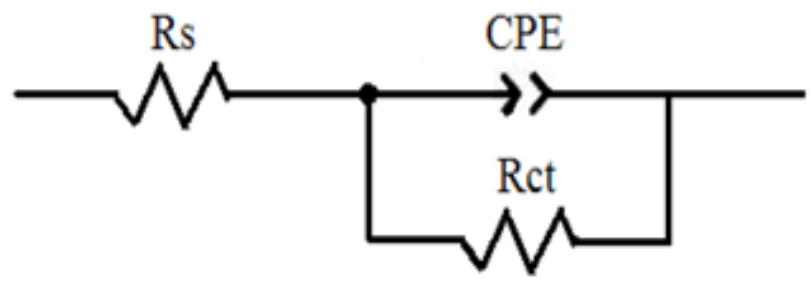

Figure 5. Electrical equivalent circuit of the metal/electrolyte interface.

The electrochemical system (carbon steel $/ \mathrm{HCl}$ ) is characterized by the ability $\mathrm{CPE}$; this is verified on Nyquist plots. The impedance parameters from this study by applying the model proposed with the CPE and the inhibitory efficiency at different concentrations of inhibitor DMOPB are given in Table 3. 
Table 3. Impedance parameters for corrosion of carbon steel in $1.0 \mathrm{M} \mathrm{HCl}$ in the absence and presence of different concentrations of DMOPB at $303 \mathrm{~K}$.

\begin{tabular}{cccccccc}
\hline Inhibitor & $\begin{array}{c}\text { Concentration } \\
(\mathbf{M})\end{array}$ & $\begin{array}{c}\boldsymbol{R}_{\mathrm{ct}} \\
\left(\mathbf{\Omega} \mathbf{c m}^{\mathbf{2}}\right)\end{array}$ & $\boldsymbol{n}$ & $\begin{array}{c}\boldsymbol{Q} \times \mathbf{1 0} \\
\left(\boldsymbol{s}^{\boldsymbol{n}} \mathbf{\Omega}^{-\mathbf{1}} \mathbf{c m}^{-\mathbf{2}}\right)\end{array}$ & $\begin{array}{c}\mathbf{C P E} \\
\left(\boldsymbol{\mu} \mathbf{F} \mathbf{c m}^{-\mathbf{2}}\right)\end{array}$ & $\begin{array}{c}\boldsymbol{E}_{\mathrm{Rct}} \\
(\mathbf{\%})\end{array}$ & $\boldsymbol{\theta}$ \\
\hline Blank & 1.0 & 29.35 & 0.87 & 17.610 & 80.22 & - & - \\
\hline \multirow{2}{*}{ DMOPB } & $10^{-3}$ & 361.40 & 0.82 & 3.366 & 12.78 & 92 & 0.92 \\
& $10^{-4}$ & 214.10 & 0.80 & 5.832 & 19.50 & 86 & 0.86 \\
& $10^{-5}$ & 192.80 & 0.80 & 6.113 & 20.14 & 85 & 0.85 \\
& $10^{-6}$ & 172.50 & 0.82 & 8.112 & 31.77 & 83 & 0.83 \\
\hline
\end{tabular}

The inhibition efficiency $E_{\mathrm{Rct}}(\%)$ got from the charge-transfer resistance is calculated using the following equation:

$$
E_{\mathrm{Rct}} \%=\frac{R_{\mathrm{ct}}^{\prime}-R_{\mathrm{ct}}}{R_{\mathrm{ct}}^{\prime}} \times 100
$$

where $R_{\mathrm{ct}}$ and $R_{\mathrm{ct}}^{\prime}$ are the charge-transfer resistance values without and with inhibitors, respectively.

Analysis of the results allows us to conclude that:

- Transfer resistance values $\left(R_{\mathrm{ct}}\right)$ are becoming more important with increasing the concentration of the inhibitor, these results signifies that the addition of the inhibitor reduce the corrosion rate. The inhibition efficiency $E_{\text {Rct }}(\%)$ evolving with the same way as the charge transfer resistance $\left(R_{\mathrm{ct}}\right)$ and reaches a maximum of the value $92 \%$ involves that the DMOPB are the good inhibitor of the corrosion of carbon steel metal.

- When the concentration of the inhibitor increases, we notice that increasing the size of the capacitive loop, which can be attributed to the process charge transfer, is well marked and that the value of the impedance obtained in the case of the blank control is smaller than those obtained with presence of the inhibitor.

- With the addition of the DMOPB the capacitive nature of the double layer (CPE) decreases to 80.22 for reference, to 12.78 for $10^{-3} \mathrm{M}$ DMOPB, which can result from a decrease in local dielectric constant and/or an increase in the thickness of the electrical double layer, suggests that the inhibitor molecules function by adsorption at the metal/solution interface [20].

- The values $n$ are close to 1 which means that the surface is not really heterogeneous.

As an example, the Nyquist plot for DMOPB in $1 \mathrm{M} \mathrm{HCl}$ is presented in Figure 6. Excellent fit with this model was obtained with our experimental data (Figure 6). 


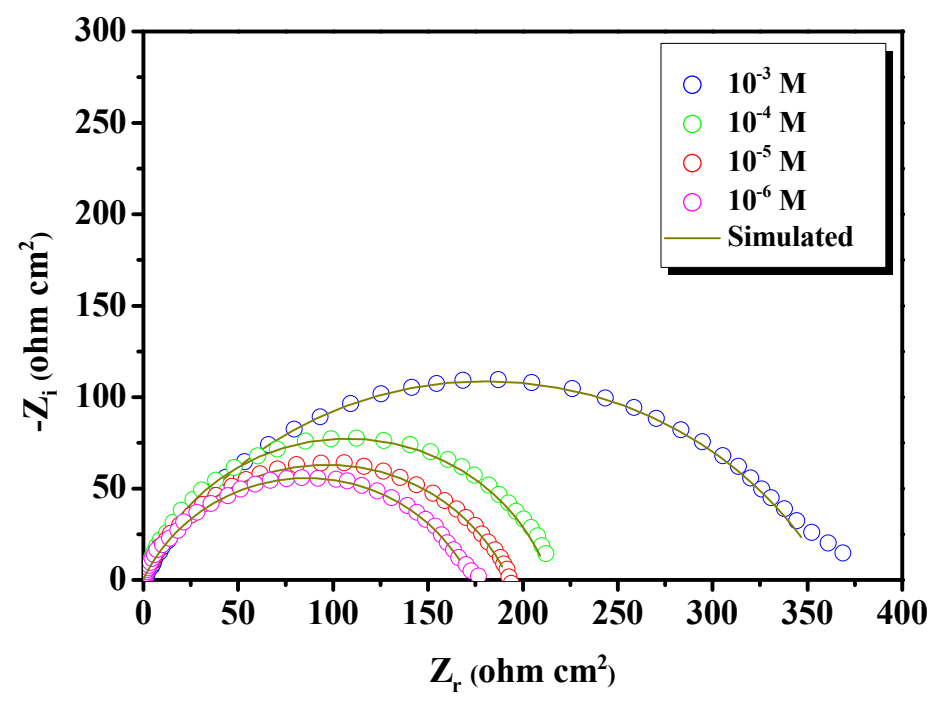

Figure 6. EIS Nyquist plots for carbon steel in $1.0 \mathrm{M} \mathrm{HCl}$ with DMOPB interface: dotted lines - experimental data; dashed line - calculated.

It is observed that the fitted data match the experimental with an average error of about $0.01 \%$. Results obtained from EIS measurements are in good agreement with that obtained from both potentiodynamic polarization and weight loss measurements.

\subsection{Effect of temperature}

The corrosive environment temperature is one of the factors that may cause the inhibition efficiency of a compound and the comportment of substrates in a given environment. Given the importance of this factor, we are studied the effect of temperature, in order to gain the activation parameters of the corrosion process, polarization tests, were carried out at various temperatures $(303-333 \mathrm{~K})$ in the absence and presence of $10^{-3} \mathrm{M}$ of DMOPB, as shown in Figures 7, 8. The values of corrosion parameters and the inhibitory efficiency as a function of temperature are given in Table 4. As seen from Figures 7, 8 and Table 4, the study of the influence of temperature on the inhibition action of the inhibitor show that the efficiency changes slightly with temperature in the range of $303-333 \mathrm{~K}$. The corrosion current density increases with increasing of temperature, in both uninhibited and inhibited solutions, the DMOPB can be regarded as temperature-independent inhibitor. The results in this table show that the inhibitor is a stable product that maintains its efficacy even at high temperatures, which puts it in the category of substances promised for industrial uses in the field of corrosion of iron and steel in environment acid. The variation of the logarithm of the corrosion rate as a function of the inverse of the absolute temperature is a straight line (Figure 9), for steel in the corrosive medium with and without addition of $10^{-3} \mathrm{M}$ of DMOPB. 
Table 4. The influence of temperature on the electrochemical parameters for carbon steel electrode immersed in $1.0 \mathrm{M} \mathrm{HCl}$ and $1.0 \mathrm{M} \mathrm{HCl}+10^{-3} \mathrm{M}$ of DMOPB.

\begin{tabular}{|c|c|c|c|c|c|}
\hline Inhibitor & $\begin{array}{c}\text { Temperature } \\
\text { (K) }\end{array}$ & $\begin{array}{c}-E_{\text {corr }} \\
(\mathrm{mV} / \mathrm{SCE})\end{array}$ & $\begin{array}{c}-\beta c \\
\left(m V \operatorname{dec}^{-1}\right)\end{array}$ & $\begin{array}{c}I_{\text {corr }} \\
\left(\mu \mathrm{A} \mathrm{cm}^{-2}\right)\end{array}$ & $E_{\mathrm{I}}(\%)$ \\
\hline \multirow{4}{*}{ Blank } & 303 & 496 & 162.5 & 564 & - \\
\hline & 313 & 498 & 154.5 & 773 & - \\
\hline & 323 & 492 & 176.0 & 1244 & - \\
\hline & 333 & 497 & 192.0 & 1650 & - \\
\hline \multirow{4}{*}{ DMOPB } & 303 & 470 & 156.0 & 45.7 & 92 \\
\hline & 313 & 468 & 144.2 & 98.0 & 87 \\
\hline & 323 & 497 & 165.8 & 182.0 & 85 \\
\hline & 333 & 512 & 158.0 & 320.0 & 80 \\
\hline
\end{tabular}

Straight lines are obtained with a slope of $\left(-\mathrm{E}_{\mathrm{a}} / \mathrm{R}\right)$. Activation parameters obtained from this graph are given in Table 5. We can therefore calculate the apparent activation energy from the Arrhenius relationship:

$$
I_{\text {corr }}=A \exp \left(\frac{-E_{\mathrm{a}}}{R T}\right)
$$

where $A$ is the pre-exponential factor, $E_{\mathrm{a}}$ is the apparent activation energy of the corrosion process, $R$ is the gas constant and $T$ is the absolute temperature.

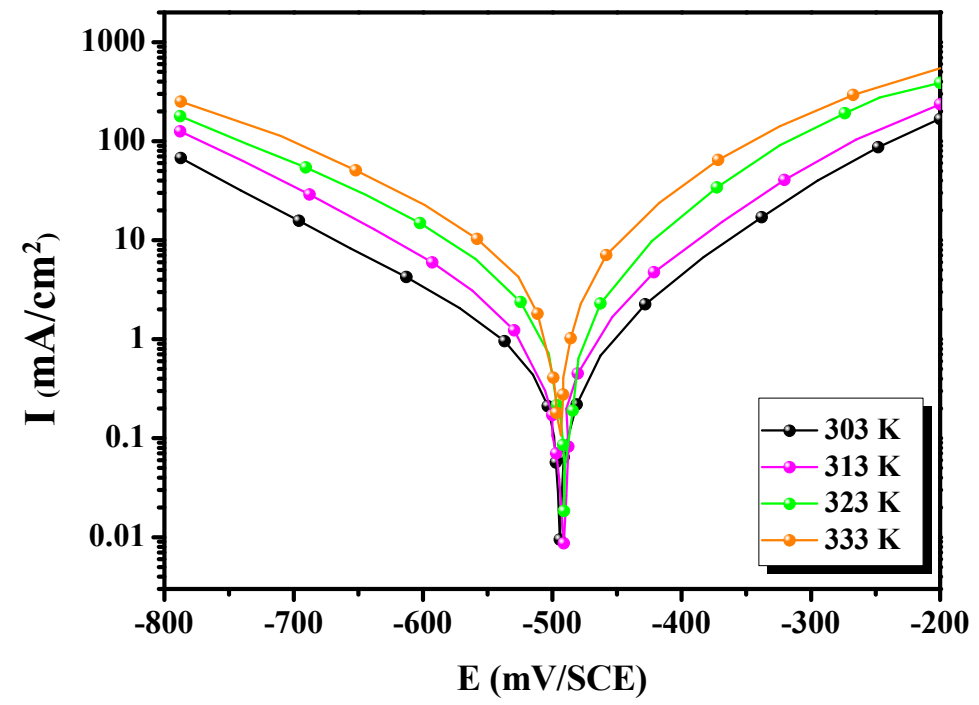

Figure 7. Potentiodynamic polarization curves of carbon steel in $1.0 \mathrm{M} \mathrm{HCl}$ at different temperatures. 


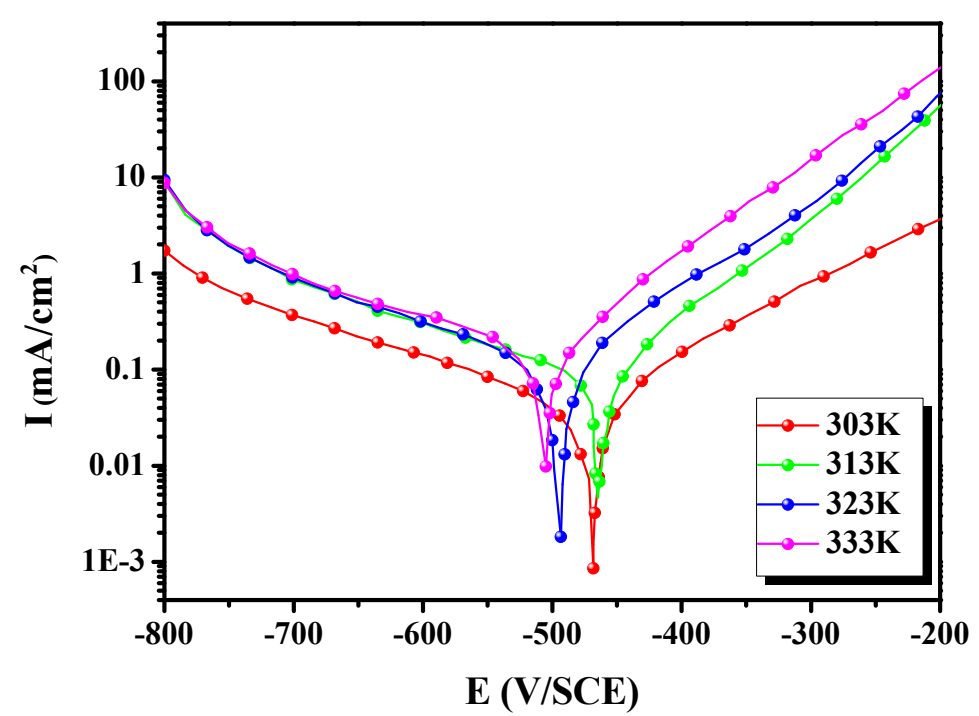

Figure 8. Potentiodynamic polarization curves of carbon steel in $1.0 \mathrm{M} \mathrm{HCl}$ in the presence of $10^{-3} \mathrm{M}$ of DMOPB at different temperatures.

From Table 5, it is observed that the values of $E_{\mathrm{a}}$ obtained in presence of DMOPB are higher than that obtained in the inhibitor-free solution. This increase of activation of the corrosion process in the presence of inhibitor compared to that in its absence may be interpreted as an electrostatic adsorption process of inhibitor on the carbon steel surface and that is attributed to the existence of physical process in the adsorption of inhibitor on carbon steel surface [21].

Table 5 Corrosion kinetic parameters for mild steel in $1.0 \mathrm{M} \mathrm{HCl}$ in the presence and absence of $10^{-3} \mathrm{M}$ DMOPB.

\begin{tabular}{cccccc}
\hline Inhibitor & $\boldsymbol{R}^{\mathbf{2}}$ & $\begin{array}{c}\boldsymbol{E}_{\mathbf{a}} \\
(\mathbf{k J} / \mathbf{m o l})\end{array}$ & $\begin{array}{c}\Delta \boldsymbol{H}_{\mathrm{a}}^{*} \\
(\mathbf{k J} / \mathbf{m o l})\end{array}$ & $\begin{array}{c}\Delta \boldsymbol{S}_{\mathrm{a}}^{*} \\
\left(\mathbf{J} \mathbf{~ m o l}^{-1} \mathbf{K}^{-\mathbf{1}}\right)\end{array}$ & $\boldsymbol{E}_{\mathrm{a}}-\Delta \boldsymbol{H}_{\mathrm{a}}^{*}$ \\
\hline Blank & 0.9953 & 31.00 & 28.35 & -98.8 & 2.65 \\
DMOPB & 0.9999 & 54.22 & 51.58 & 42.57 & 2.64 \\
\hline
\end{tabular}

Kinetic parameters, such as entropy of corrosion process and enthalpy, can be evaluated from the effect of temperature. An alternative formulation of Arrhenius equation:

$$
I_{\text {corr }}=\frac{R T}{N h} \exp \left(\frac{\Delta S_{\mathrm{a}}^{*}}{R}\right) \exp \left(-\frac{\Delta H_{\mathrm{a}}^{*}}{R T}\right)
$$

where $N$ is the Avogadro's number, $h$ the Plank's constant, $R$ is the perfect gas constant, $\Delta S^{*}$ and $\Delta H^{*}$ are the entropy and enthalpy of activation, respectively. 


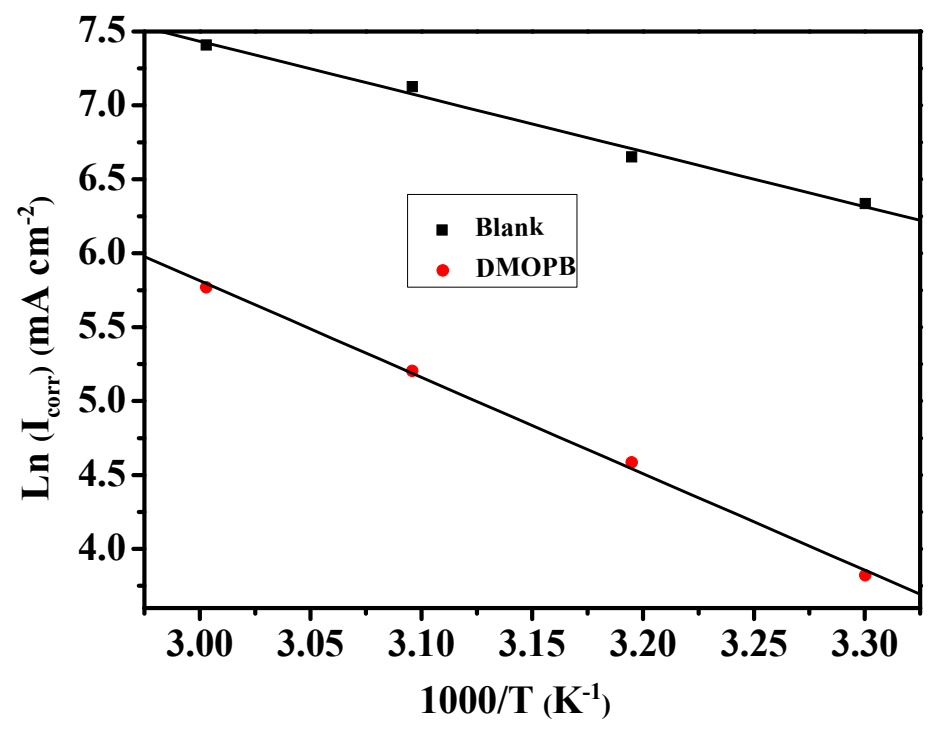

Figure 9. Arrhenius straight lines for carbon steel in $1.0 \mathrm{M} \mathrm{HCl}$ and $1.0 \mathrm{M} \mathrm{HCl}+10^{-3} \mathrm{M}$ DMOPB.

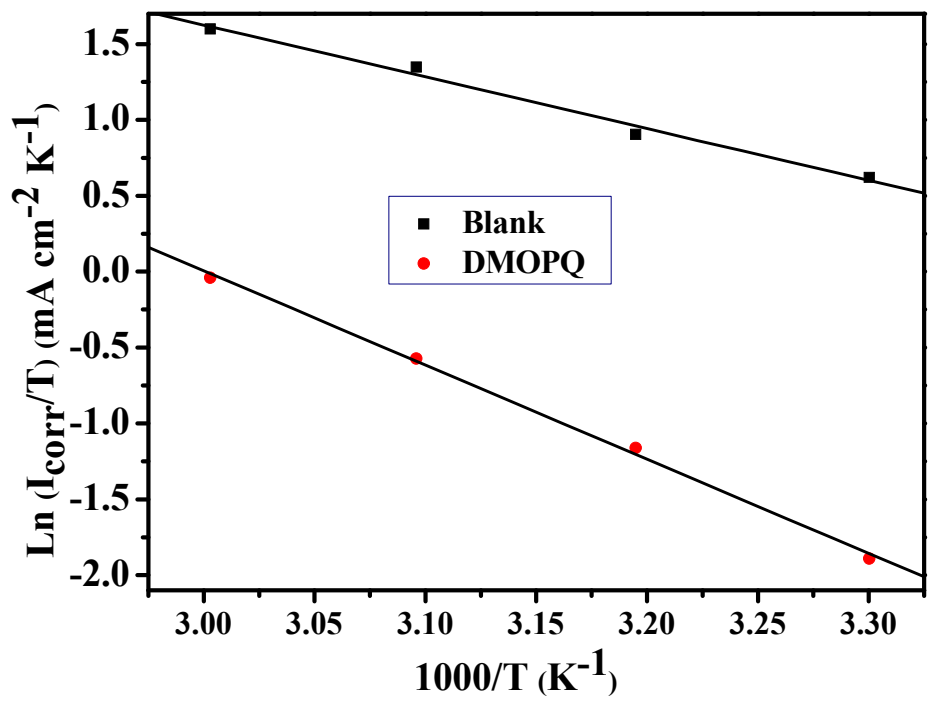

Figure 10. Transition state plots for carbon steel in $1.0 \mathrm{M} \mathrm{HCl}$ and $1.0 \mathrm{M} \mathrm{HCl}+10^{-3} \mathrm{M}$ DMOPB.

Figure 10 shows a plot of $\ln \left(I_{\text {corr }} / T\right)$ against $1 / T$ for DMOPB and blank. Straight lines are obtained with a slope $\left(-\Delta H_{\mathrm{a}}^{*} / R\right)$ and intercept $\left(\ln R / N h+\Delta S_{\mathrm{a}}^{*} / R\right)$, from this relation the values of $\Delta H_{\mathrm{a}}^{*}$ and $\Delta S_{\mathrm{a}}^{*}$ can be calculated (Table 5 and Figure 10). 
The data from Table 5 show that the thermodynamic parameters $\left(\Delta H^{*}\right.$ and $\left.\Delta S^{*}\right)$ of the dissolution reaction of carbon steel in $1 \mathrm{M} \mathrm{HCl}$ in the presence of the DMOPB are higher than those of the uninhibited solution.

- The positive values of $\Delta H^{*}$ mean that the dissolution reaction is an endothermic process and that the dissolution of carbon steel is difficult.

- The value of $\Delta S_{\mathrm{a}}^{*}$ is higher for the inhibited solution than that for the uninhibited solution. This phenomenon suggested that a decrease in randomness occurred on going from reactants to the activated complex. This might be the result of the adsorption of organic inhibitor molecule from the acidic solution which could be regarded as a quasi-substitution process between the organic compound in the aqueous phase and water molecules at electrode surface [22].

\section{Adsorption considerations}

Additional information about the properties of the tested compounds may be provided from the kind of adsorption isotherm. The most commonly used isotherms are Langmuir, Frumkin, Temkin, Parsons, etc. The adsorption isotherm can provide more information on the interaction between the metal surface and the DMOPB inhibitor molecule. Several adsorption isotherms were tested and we found that the inhibitor adsorb on the carbon steel surface according to the Langmuir kind isotherm model which obeys the relation:

$$
\frac{C}{\theta}=\frac{1}{K}+C,
$$

where $C$ is concentration of inhibitor, $\theta$ is the surface coverage and $K$ is the equilibrium constant of the adsorption process.

Figure 11 (plot of $C / \theta$ versus $C$ ) gives straight line with slope near to 1 , meaning that the adsorption of the inhibitor under consideration on carbon steel/acidic solution interface obeys Langmuir's adsorption. The thermodynamic parameters for adsorption shown in Table 6 were calculated using the values of $K$ according to the following equation:

$$
\log K=-1.74-\left(-\frac{\Delta G_{\text {ads }}}{2.303 R T}\right),
$$

where $\Delta G_{\text {ads }}$ is the free energy of adsorption.

The negative sign of $\Delta G_{\text {ads }}$ suggest the spontaneity of the adsorption process and stability of the adsorbed layer on the electrode surface [23]. It is well known that the absolute values of $\Delta G_{\text {ads }}$ of the order of $20 \mathrm{~kJ} \mathrm{~mol}^{-1}$ or lower indicate physisorption; those of the order of $40 \mathrm{~kJ} \mathrm{~mol}^{-1}$ or higher involve charge sharing or a transfer from the inhibitor molecules to the metal surface to form a co-ordinate type of bond [24]. Accordingly, the values of $\Delta G_{\text {ads }}$ obtained in the present study indicate that the DMOPB is chemically adsorbed on the charged carbon steel surface. 


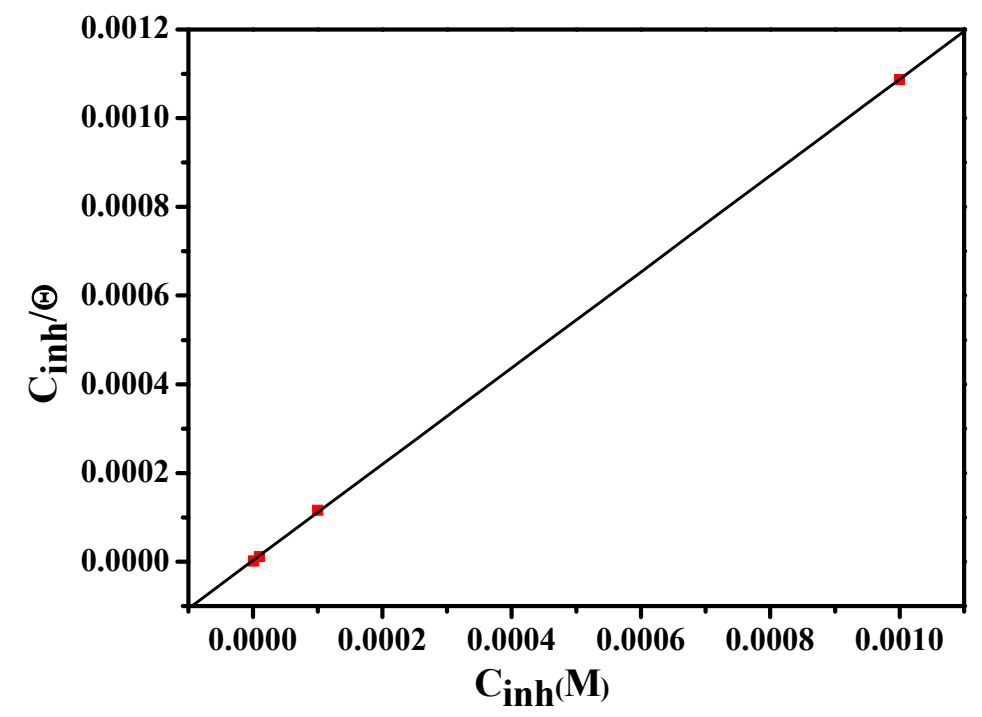

Figure 11. Langmuir adsorption of DMOPB on the carbon steel surface in $1.0 \mathrm{M} \mathrm{HCl}$ solution at $303 \mathrm{~K}$.

Table 6. Thermodynamic parameters for the adsorption of $10^{-3} \mathrm{M}$ DMOPB in $1.0 \mathrm{M} \mathrm{HCl}$ on the carbon steel at $303 \mathrm{~K}$.

\begin{tabular}{ccccc}
\hline Inhibitor & Slope & $\boldsymbol{K}_{\text {ads }}\left(\mathbf{M}^{-\mathbf{1}}\right)$ & $\boldsymbol{R}^{\mathbf{2}}$ & $\Delta \boldsymbol{G}_{\text {ads }}^{\mathbf{0}}(\mathrm{kJ} / \mathbf{m o l})$ \\
\hline DMOPB & 1.08 & 358351.01 & 0.99998 & $\mathbf{- 4 2 . 3 1}$ \\
\hline
\end{tabular}

\subsection{Quantum mechanical studies}

\subsubsection{Global molecular structure:}

Figure 12 shows the optimized geometry, the HOMO density distribution and the LUMO density distribution for DMOPB (neutral molecule) in gas phase obtained with DFT at the B3LYP/6-31G (d,p) level of theory. Analysis of Figure 12 shows that the distribution of two energies HOMO and LUMO localized in the atoms of pyridinium cycle, consequently this is the favorite sites for interaction with the metal surface. The total energy of the DMOPB is equal to $21966.08 \mathrm{eV}$.

Table 7. Quantum chemical parameters for DMOPB calculated using B3LYP/ 6-31G (d,p).

\begin{tabular}{cccccccc}
\hline$\mu($ debye $)$ & TE $(\mathrm{eV})$ & $\begin{array}{c}E_{\mathrm{HOMO}} \\
(\mathrm{eV})\end{array}$ & $\begin{array}{c}E_{\text {LUMO }} \\
(\mathbf{e V})\end{array}$ & $\begin{array}{c}\Delta E_{\text {gap }} \\
(\mathbf{e V})\end{array}$ & $\begin{array}{c}\text { IE } \\
(\mathrm{eV})\end{array}$ & $\begin{array}{c}\mathrm{EA} \\
(\mathrm{eV})\end{array}$ & $\Delta N$ \\
\hline $\mathbf{1 . 1 6 2 6}$ & 21966.08 & -2.4623 & 0.2898 & 2.7521 & 2.4623 & -0.2898 & 1.08625 \\
\hline
\end{tabular}


Table 7 shows some of the key quantum chemical parameters computed using DFT method. These are mainly the energies of the lowest unoccupied $\left(E_{\mathrm{LUMO}}\right)$ molecular orbitals and highest occupied $\left(E_{\mathrm{HOMO}}\right)$, energy of the gap, $\Delta E\left(E_{\mathrm{LUMO}}-E_{\mathrm{HOMO}}\right)$ and dipole moment $(\mu)$. These quantum chemical parameters were obtained after geometric optimization with respect to all nuclear coordinates. There is a general consensus by several researchers that the more negatively charged a heteroatom is, the more it can be adsorbed on the metal surface through the donor-acceptor type reaction [25].
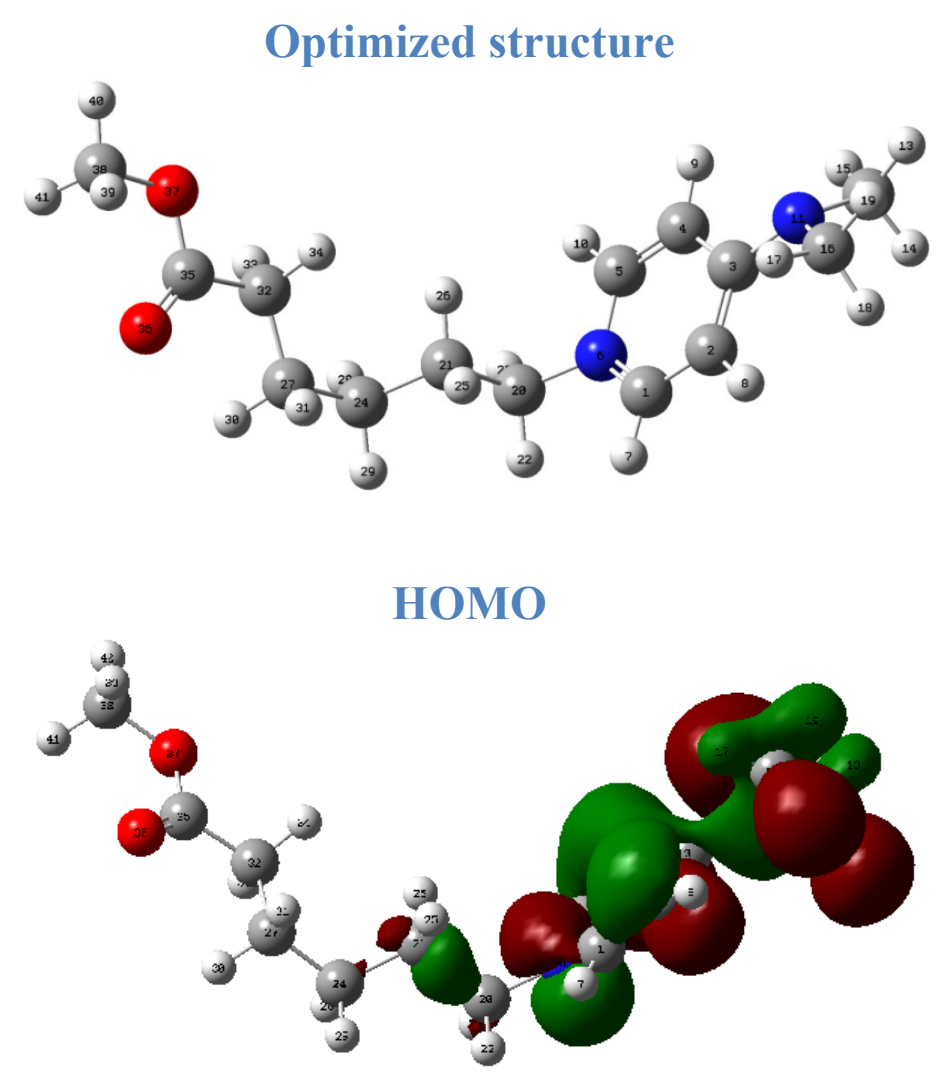

\section{LUMO}

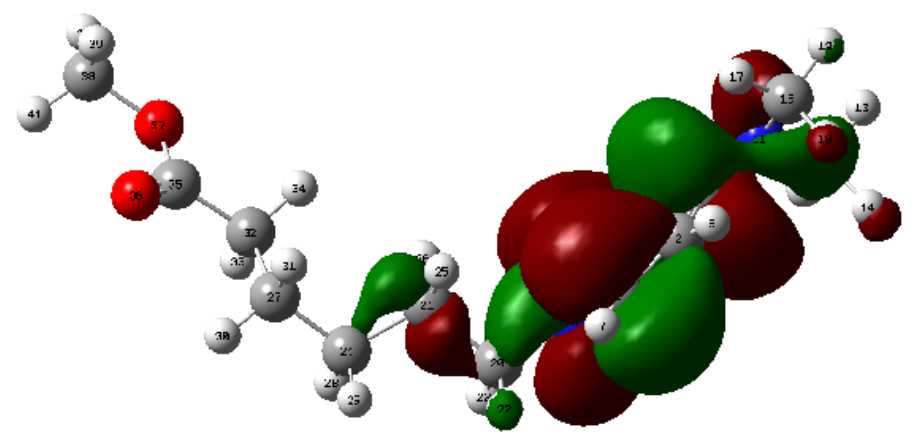

Figure 12. Optimized structure of DMOPB, and Frontier molecular orbital (FMO) density distribution of DMOPB: HOMO and LUMO. 
It has been reported that $E_{\mathrm{HOMO}}$ is often associated with the electron donating ability of a molecule, whereas $E_{\mathrm{LUMO}}$ indicates its ability to accept electrons. The high values of $E_{\text {номо }}(-2.4623 \mathrm{eV})$ are likely to indicate a tendency of the molecule to donate electrons to appropriate acceptor molecules with low energy and empty molecular orbital, whereas the value of $E_{\text {LUMO }}(0.2898 \mathrm{eV})$ indicates its ability of the molecule to accept electrons. Consequently, the value of $\Delta E_{\text {gap }}$ informs about the reactivity of a molecule toward other chemical species. Molecules with large value of $\Delta \mathrm{E}$ are highly stable (low reactivity) while molecules with small values of $\Delta \mathrm{E}$ have a high reactivity. The value of $\Delta E_{\text {gap }}$ means that DMOPB would easily bind onto the metal surface leading to high inhibition efficiency. The total energy of the DMOPB is equal to $21966.08 \mathrm{eV}$. This result indicated that DMOPB is favorably adsorbed through the active centers of adsorption. The dipole moment gives information about the polarity of the compounds and also informs about the reactivity of molecules. Lower values of dipole moment $(\mu)$ will favor accumulation of the inhibitor in the surface layer and therefore higher inhibition efficiency [26].

\subsubsection{Active sites}

Molecular electrostatic potential is very important descriptor for determining active sites, reactivity, and structure-activity relationship of molecules. The optimized molecular structure with Mulliken charges, NBO charges values and the total electron density surface mapped with molecular electrostatic potential (MEP) of DMOPB are shown in Figure $13 \mathrm{a}-\mathrm{c}$. The color scheme for the MEP surface is red, electron rich, partially negative charge; blue, electron deficient, partially positive charge; light blue, slightly electron deficient region; yellow, slightly electron rich region; green, neutral; respectively.

As can be seen from Figure 13c, that more electron rich regions are mainly localized around the heteroatoms. Mulliken charges of the atoms are shown in Figure 13a. Several authors agree that the more negatively charged heteroatom is the merrier is its ability to adsorb on the metal surface, through donor-acceptor type reaction [27]. Examination of these results shows that all the heteroatoms and some carbon atoms have the negative charges with a high electron density. These atoms thus behave as nucleophilic centers when they interact with the iron surface [28]. Natural bond orbital (NBO) analysis provides an efficient method for studying intra- and intermolecular bonding and interaction among bonds, and also provides a convenient basis for investigating charge transfer or conjugative interaction in molecular systems. The NBO calculation is performed using NBO 3.1 program implemented in the Gaussian 03 package at the DFT/B3LYP/6-31G $(d, p)$ level theory and presented in Figure 13b. The nitrogen, oxygen and the some carbon atoms of DMOPB have the negative charges, which are the most favored sites for bonding to mild steel surface through donating electrons. However, the positive charges atoms can give and receive the electron to and from metal, respectively [29]. $\pi$-Delocalization in investigated molecule plays an important role to determine the active sites. In molecule, there is a $\pi$ delocalization on oxygen atom. Therefore, environment of oxygen atom $(\mathrm{O} 36)$ is redder than other oxygen atom in same molecule. This result means that $\mathrm{O} 36$ atom is the more 
active site in molecule. On the other hand, the environment of N11 atom is redder than other nitrogen atoms. This result may be due to the same reason [30].

(a)

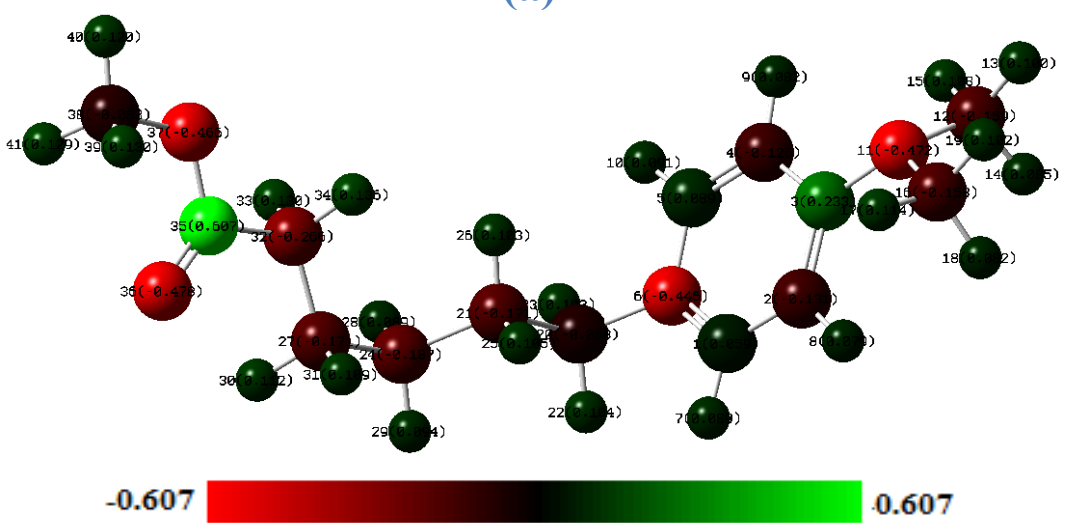

(b)

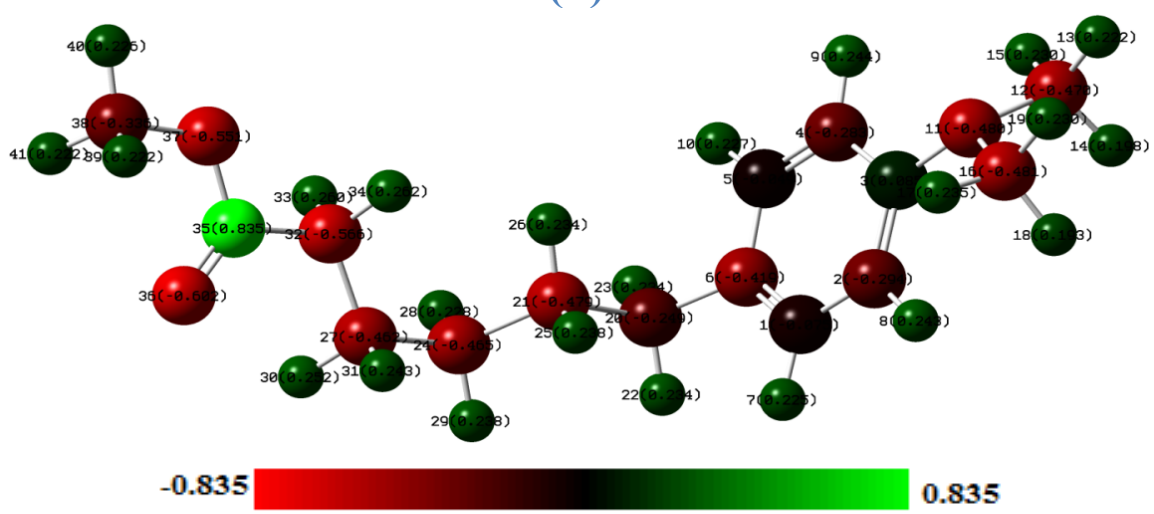

(c)
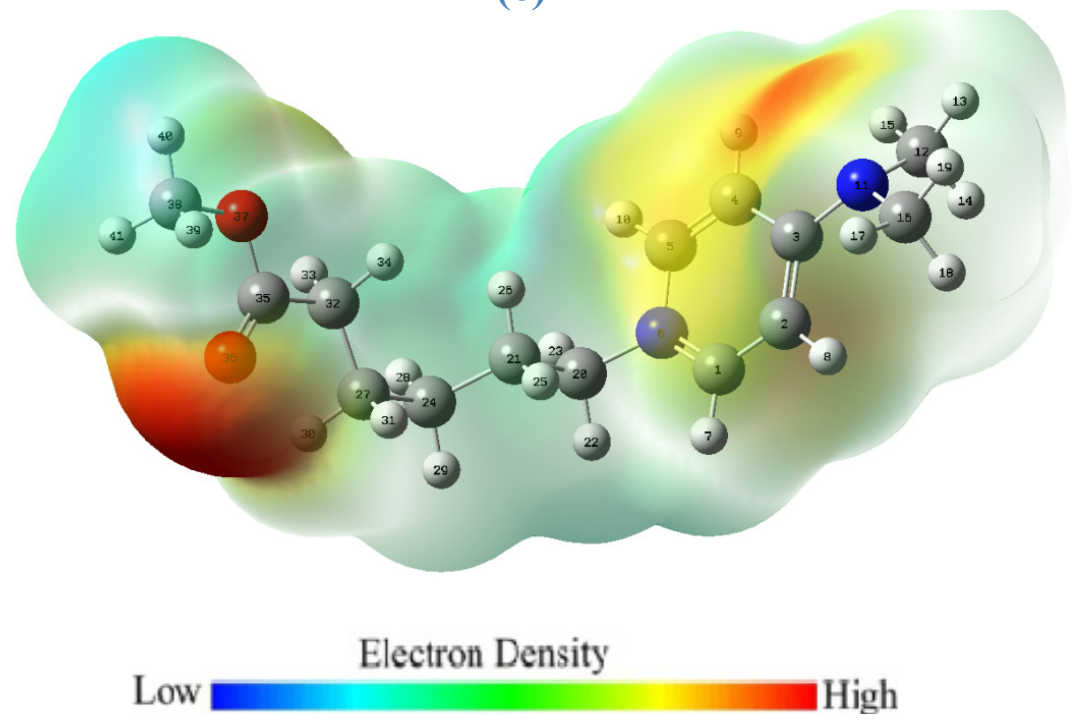

Figure 13. Quantum chemical results of DMOPB molecule calculated by the DFT/B3LYP method with 6$31 \mathrm{G}(\mathrm{d}, \mathrm{p})$ basis set: (a) optimized molecular structure with Mulliken (a), NBO charge values (b); and (c) total electron density surface mapped with electrostatic potential. 
In order to analyze local reactivity as well as local nucleophilic or electrophilic feature in the molecules, the Fukui functions are by far the most important local reactivity index [31]. Using a scheme of finite difference approximations, this procedure condenses the values around each atomic site into a single value that characterizes the atom in the molecule. With this approximation, the condensed Fukui function becomes:

$$
\begin{aligned}
& f_{k}^{+}=P_{k}(N+1)-P_{k}(N) \text { (For nucleophilic attack), } \\
& f_{k}^{-}=P_{k}(N)-P_{k}(N-1) \text { (For electrophilic attack), }
\end{aligned}
$$

where $P_{k}(N+1), P_{k}(N), P_{k}(N-1)$ represent charge values of atom $k$ for anion, neutral, and cation, respectively.

An analysis of the Fukui indices for nucleophilic and electrophilic sites is presented in Table 8 . Generally, the high value of $f_{k}^{+}$means the high capacity of the atom to accept electrons when attacked by a nucleophilic reagent. On the other hand, the preferred site for electrophilic attack is the atom in the molecule where $f_{k}^{-}$has the highest value.

Table 8 Natural population and Fukui functions of the studied inhibitor calculated at B3LYP/6-31G(d,p).

\begin{tabular}{cccccc}
\hline Atom & $\mathbf{P}(\mathbf{N})$ & $\boldsymbol{P}(\boldsymbol{N}+\mathbf{1})$ & $\boldsymbol{P}(\boldsymbol{N}-\mathbf{1})$ & $\boldsymbol{f}_{\boldsymbol{k}}^{+}$ & $\boldsymbol{f}_{\boldsymbol{k}}^{-}$ \\
\hline C 1 & 6.07427 & 6.15375 & 5.92183 & $\mathbf{0 . 0 7 9 4 8}$ & $\mathbf{0 . 1 5 2 4 4}$ \\
C 2 & 6.29393 & 6.29219 & 6.30290 & -0.00174 & -0.00897 \\
C 3 & 5.91531 & 6.07953 & 5.72928 & $\mathbf{0 . 1 6 4 2 2}$ & $\mathbf{0 . 1 8 6 0 3}$ \\
C 4 & 6.28256 & 6.29495 & 6.27060 & 0.01239 & 0.01196 \\
C 5 & 6.04944 & 6.14518 & 5.94419 & $\mathbf{0 . 0 9 5 7 4}$ & $\mathbf{0 . 1 0 5 2 5}$ \\
N 6 & 7.41869 & 7.47794 & 7.32956 & $\mathbf{0 . 0 5 9 2 5}$ & $\mathbf{0 . 0 8 9 1 3}$ \\
H 7 & 0.77452 & 0.80819 & 0.72773 & 0.03367 & 0.04679 \\
H 8 & 0.75675 & 0.78966 & 0.71530 & 0.03291 & 0.04145 \\
H 9 & 0.75556 & 0.78975 & 0.71360 & 0.03419 & 0.04196 \\
H 10 & 0.77319 & 0.80842 & 0.72807 & 0.03523 & 0.04512 \\
N 11 & 7.48024 & 7.44872 & 7.42640 & -0.03152 & $\mathbf{0 . 0 5 3 8 4}$ \\
C 12 & 6.47022 & 6.45853 & 6.48778 & -0.01169 & -0.01756 \\
H 13 & 0.77770 & 0.79359 & 0.74145 & 0.01589 & 0.03625 \\
H 14 & 0.80225 & 0.81341 & 0.76572 & 0.01116 & 0.03653 \\
H 15 & 0.76937 & 0.81154 & 0.75575 & 0.04217 & 0.01362 \\
C 16 & 6.48119 & 6.45854 & 6.50412 & -0.02265 & -0.02293 \\
H 17 & 0.76490 & 0.81186 & 0.74982 & 0.04696 & 0.01508 \\
H 18 & 0.80698 & 0.81323 & 0.77405 & 0.00625 & 0.03293 \\
H 19 & 0.76988 & 0.79366 & 0.73329 & 0.02378 & 0.03659 \\
C 20 & 6.24925 & 6.23716 & 6.26865 & -0.01209 & -0.0194 \\
C 21 & 6.47913 & 6.47870 & 6.47360 & -0.00043 & 0.00553 \\
H 22 & 0.76558 & 0.79849 & 0.73664 & 0.03291 & 0.02894
\end{tabular}




\begin{tabular}{cccccc}
\hline Atom & $\mathbf{P}(\mathbf{N})$ & $\boldsymbol{P}(\boldsymbol{N}+\mathbf{1})$ & $\boldsymbol{P}(\boldsymbol{N}-\mathbf{1})$ & $\boldsymbol{f}_{\boldsymbol{k}}^{+}$ & $\boldsymbol{f}_{\boldsymbol{k}}^{-}$ \\
\hline H 23 & 0.76631 & 0.79709 & 0.73663 & 0.03078 & 0.02968 \\
C 24 & 6.46477 & 6.45976 & 6.46976 & -0.00501 & -0.00499 \\
H 25 & 0.76217 & 0.76920 & 0.75734 & 0.00703 & 0.00483 \\
H 26 & 0.76589 & 0.76793 & 0.75892 & 0.00204 & 0.00697 \\
C 27 & 6.46234 & 6.45535 & 6.46652 & -0.00699 & -0.00418 \\
H 28 & 0.77196 & 0.78398 & 0.76006 & 0.01202 & 0.0119 \\
H 29 & 0.76170 & 0.77870 & 0.75135 & 0.017 & 0.01035 \\
H 30 & 0.74782 & 0.76843 & 0.73025 & 0.02061 & 0.01757 \\
H 31 & 0.75696 & 0.76180 & 0.75264 & 0.00484 & 0.00432 \\
C 32 & 6.56635 & 6.55140 & 6.56756 & -0.01495 & -0.00121 \\
H 33 & 0.74041 & 0.76850 & 0.73664 & 0.02809 & 0.00377 \\
H 34 & 0.73812 & 0.76379 & 0.74809 & 0.02567 & -0.00997 \\
C 35 & 5.16503 & 5.27430 & 5.16817 & $\mathbf{0 . 1 0 9 2 7}$ & -0.00314 \\
O 36 & 8.60191 & 8.66864 & 8.59185 & $\mathbf{0 . 0 6 6 7 3}$ & 0.01006 \\
O 37 & 8.55092 & 8.56926 & 8.55002 & 0.01834 & 0.0009 \\
C 38 & 6.33595 & 6.32887 & 6.33728 & -0.00708 & -0.00133 \\
H 39 & 0.77779 & 0.79021 & 0.77487 & 0.01242 & 0.00292 \\
H 40 & 0.77427 & 0.79257 & 0.76915 & 0.0183 & 0.00512 \\
H 41 & 0.77841 & 0.79323 & 0.77253 & 0.01482 & 0.00588 \\
\hline
\end{tabular}

It is possible to observe from Table 8 , that $\mathrm{C} 1, \mathrm{C} 3$, and $\mathrm{C} 5$ is the most susceptible sites for electrophilic attacks. The value of $f_{k}^{+}$is highest on $\mathrm{C} 1, \mathrm{C} 3, \mathrm{C} 5, \mathrm{~N} 6$, and $\mathrm{O} 36$, indicating that these atoms are likely to be engaged in a nucleophilic attack on the inhibitor. This estimation is in good agreement with obtained results from MEP, Mulliken and NBO atomic charges analyses.

\subsection{SEM analysis of metal surface}

The morphologies of the carbon steel in $1 \mathrm{M} \mathrm{HCl}$ both in presence and absence of inhibitor were recorded by SEM (Figures $14 \mathrm{a}-\mathrm{c}$ ) to establish the interaction of inhibitor molecules with the carbon steel surface. Figure 14a shows the images of the CS strips before exposing to acid. Figure 14b shows the effect of aggressive acidic solution. In the presence of inhibitor (Figure 14c) the damage of mild steel surface is obviously reduced. The SEM images revealed that the specimens immersed in the inhibitor solutions are in better conditions having smooth surface while the metal surface immersed in $1 \mathrm{M} \mathrm{HCl}$ is rough and covered with corrosion products and appeared like full of pits and cavities. This indicated that the inhibitor molecules hinder the dissolution of iron by adsorption on the steel surface and thereby reduced the rate of corrosion. 

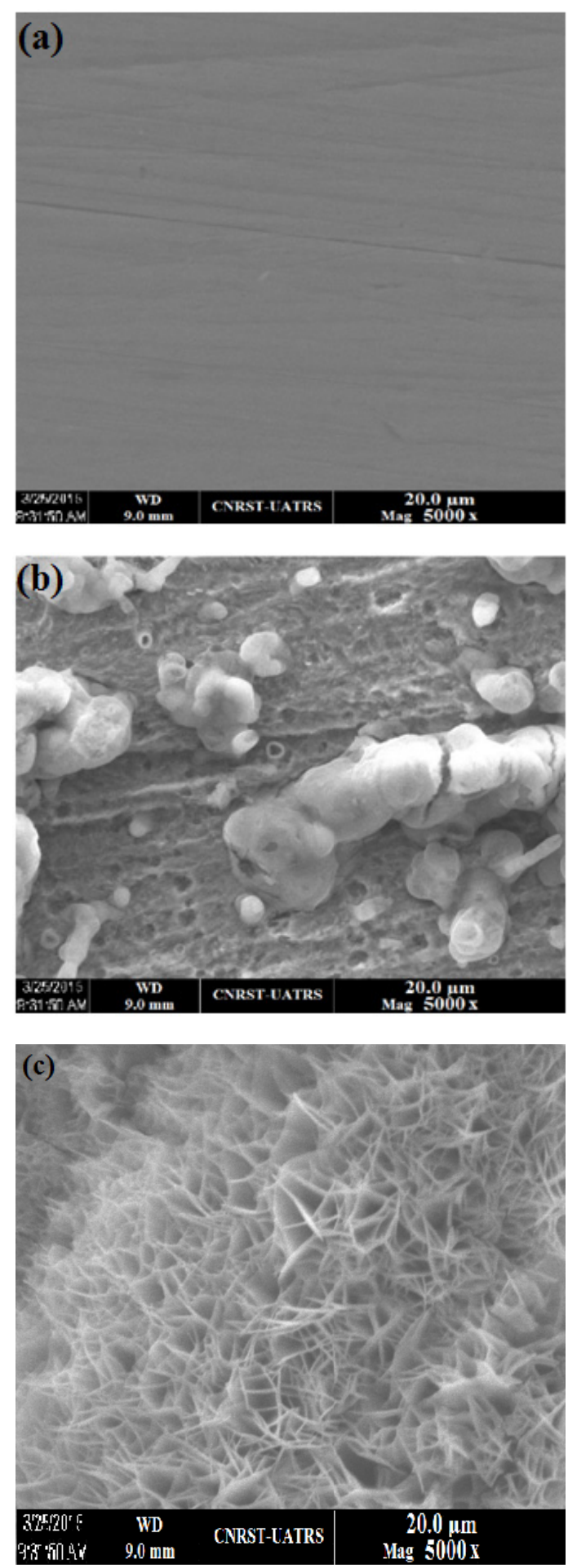

Figure 14. SEM images of carbon steel $(\times 5000)$ : (a) unexposed, (b) exposed in $1 \mathrm{M} \mathrm{HCl}$ and (c) exposed in $1 \mathrm{M} \mathrm{HCl}$ in the presence of $10^{-3} \mathrm{M}$ of DMOPB for $24 \mathrm{~h}$ at $303 \mathrm{~K}$. 


\section{Conclusion}

The electrochemical and gravimetric study of the inhibition of corrosion of carbon steel in $1 \mathrm{M} \mathrm{HCl}$ medium with the presence of DMOPB inhibitor was performed. The following conclusions can be drawn:

- The value of the inhibition efficiency increases with the concentration of the inhibitor to achieve $92 \%$ at $10^{-3} \mathrm{M}$.

- The inhibitor adsorbs to the surface of the carbon steel according to the Langmuir isotherm.

- The study of the polarization shows that the addition of this inhibitor does not change the hydrogen reduction mechanism and DMOPB as ionic liquid acts as a mixed type inhibitor.

- The increases of temperature does not affect the inhibition efficiency, therefore this inhibitor is stable at high temperature.

- The results determined by gravimetric stationary and electrochemical techniques are in good agreement.

- The high negative value of $\Delta G_{\text {ads }}^{0}$ suggests that the inhibitive effect of DMOPB is due to the formation of a chemisorbed film on the metallic surface

- Data obtained from quantum chemical calculations using DFT at the B3LYP/6$31 \mathrm{G}(\mathrm{d})$ level of theory were correlated to the inhibitive effect of pyridine derivative. Both experimental and theoretical calculations are in excellent agreement.

- The SEM image, confirm the formation of a protective film on the surface of the work electrode.

\section{Acknowledgment}

The authors would like to thank the Palestinian Ministry of Higher Education for their support. The support given through an "INCRECYT" research contract to M. Zougagh is also acknowledged.

\section{References}

1. M. Heydari and M. Javidi, Corros. Sci., 2012, 61, 148.

2. A. Bousskri, A. Anejjar, M. Messali, R. Salghi, O. Benali，Y. Karzazi， S. Jodeh, M. Zougagh, E. Ebenso and B. Hammouti, J. Mol. Liq., 2015, 211, 1000.

3. H. Zarrok, A. Zarrouk, B. Hammouti, R. Salghi, C. Jama and F. Bentiss, Corros. Sci., 2012, 64, 243.

4. A.S.H. Kim, S.B. Haabani and D.S. Eifzadeh, Appl. Surf. Sci., 2005, 239, 154.

5. A.F. Al-Ghamdi, M. Messali and S.A. Ahmed, J. Mater. Environ. Sci., 2011, 2, no. 3, 215.

6. P. Wang, S.M. Zakeeruddin, P. Comte, I. Exnar and M. Gratzel, J. Am. Chem. Soc., 2003, 125, 1166.

7. M. Messali, J. Mater. Environ. Sci., 2011, 2, 174. 
8. F.V. Rantwijk and R.A. Sheldon, Chem. Rev., 2007, 107, 2757.

9. D.Q. Zhang, L.X. Gao and G.D. Zhou, Corros. Sci., 2004, 46, 3031.

10. M.A. Ibrahim, M. Messali, Z. Moussa, A.Y. Alzahrani, S.N. Alamry and B. Hammouti, Portug. Electrochim. Acta. 2011, 29, no. 6, 375.

11. M. Messali, A. Bousskri, A. Anejjar, R. Salghi and B. Hammouti. Int. J. Electrochem. Sci., 2015, 10, 4532.

12. G. Bereket, C. Ogretir and C. Ozsahim, J. Mol. Struct., 2003, 39, 663.

13. M.J. Frisch, G.W. Trucks, H.B. Schlegel, et al., 2003, Gaussian 03, Revision B.01, Gaussian, Inc., Pittsburgh, PA.

14. G.N. Mu, X.H. Li, Q. Qu and J. Zhou, Corros. Sci., 2006, 48, 445.

15. I.A. Zaafarany and H.A. Ghulman, Int. J. Corros. Scale Inhib., 2013, 2, no. 2, 82. doi: 10.17675/2305-6894-2013-2-2-082-091

16. A. Khamis, M.M. Saleh, M.I. Awad and B.E. El-Anadouli, J. Adv. Res., 2014, 5, 637.

17. S. Muthumanickam, B. Jeyaprabha, R. Karthik, A. Elangovan and P. Prakash, Int. J. Corros. Scale Inhib., 2015, 4, no. 4, 365. doi: 10.17675/2305-6894-2015-4-4-6

18. A.S. Fouda, M.A. El-Morsy, A.A. El-Barbary and L.E. Lamloum, Int. J. Corros. Scale Inhib., 2016, 5, no. 2, 112. 10.17675/2305-6894-2016-5-2-2

19. M. Faustin, A. Maciuk, P. Salvin, C. Roos and M. Lebrini, Corros. Sci., 2015, 92, 287.

20. M. Lagrenée, B.M. Mernari, M. Bouanis, M. Traisnel and F. Bentiss, Corros. Sci., 2002, 44, no. 3, 573.

21. E.F. El Sherbini, Mater. Chem. Phys., 1999, 60, 286.

22. E.E. Oguzie, Corros. Sci., 2007, 49, 1527.

23. I. A. Zaafarany, Int. J. Corros. Scale Inhib., 2014, 3, no. 1, 12. doi: $\underline{10.17675 / 2305-}$ 6894-2014-3-1-012-027

24. O. Benali, L. Larabi, M. Traisnel, L. Gengenbre and Y. Harek, Appl. Surf. Sci., 2007, 253, 6130 .

25. W. Li, Q. He, C. Pei and B. Hou, Electrochim. Acta, 2007, 52, 6386.

26. N. Khalil, Electrochim Acta, 2003, 48, 2635.

27. N.O. Obi-Egbedi, K.E. Essien, I.B. Obot and E.E. Ebenso, Int. J. Electrochem. Sci., 2011, 6, 913.

28. M. Ozcan, I. Dehri and M. Erbil, Appl. Surf. Sci., 2004, 236, 155.

29. D. Daoud, T. Douadi, H. Hamani, S. Chafaa and M. Al-Noaimi, Corros. Sci., 2015, 94, 21.

30. Z. El Adnani, M. Mcharfi, M. Sfaira, M. Benzakour, A.T. Benjelloun and M. Ebn Touhami, Corros. Sci., 2013, 68, 223.

31. P. Fuentealba, P. Perez and R. Contreras, J. Chem. Phys., 2000, 113, 2544. 